\title{
A trio of infectious diseases and pulmonary embolism: A developing world's reality
}

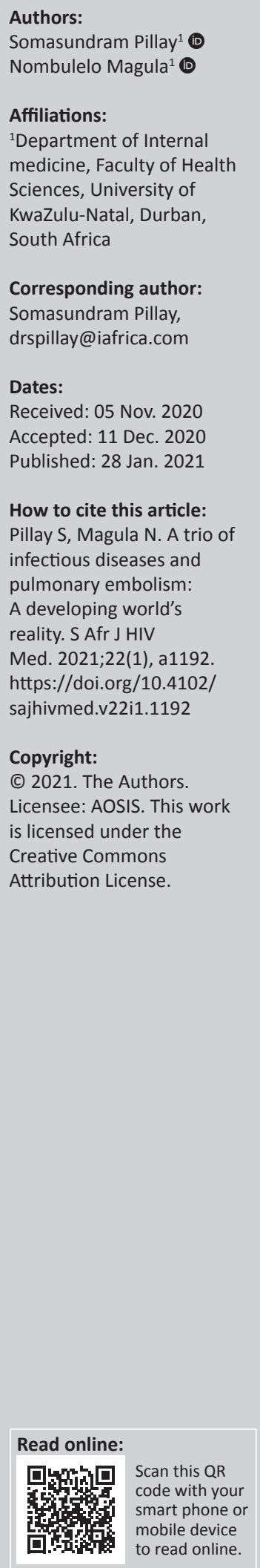

Introduction: Human immunodeficiency virus (HIV), Tuberculosis (TB) and coronavirus disease (COVID-19) infections independently possess the ability to trigger formation of venous thromboembolism (VTE) and pulmonary embolism (PE). To the authors' knowledge, this is the first case report describing the presence of $\mathrm{PE}$ in a patient with all three aforementioned infectious co-morbidities.

Presentation: A patient living with HIV with virological failure secondary to defaulting antiretroviral therapy (ART) presented with hypoxia, clinical and radiological features suggestive of community-acquired pneumonia (CAP) with raised inflammatory markers and D-dimer levels.

Management: She was commenced on prophylactic anticoagulation, supplemental oxygen and empirical antibiotics targeting CAP and pneumocystis jiroveci pneumonia, swabbed for COVID-19 infection and had sputa sent for Gene Xpert ${ }^{\circledR}$ TB testing. A day later, COVID-19 results returned positive and the patient was transferred to isolation and added onto dexamethasone and therapeutic anticoagulation. Sputa returned positive for mycobacterium TB a day later, and anti-tuberculosis therapy was added. She remained persistently hypoxic, with a Well's score of 3 placing her at moderate risk for PE, which prompted for a computed tomography pulmonary angiogram (CTPA) being ordered, which demonstrated left lower lobe subsegmental PE. Warfarin was added to her regimen. She was discharged on day 18 with a therapeutic international normalised ratio (INR) and not requiring oxygen therapy.

Conclusion: This scenario is relevant in low to middle-income countries. The utilisation of a raised D-Dimer in the setting of all four coexisting conditions in arriving at a definite diagnosis remains uncertain. We noted that despite our index patient being on thromboprophylaxis, she developed PE highlighting the need for increased vigilance in all COVID-19 patients, even those on prophylactic anticoagulation.

Keywords: HIV; tuberculosis; COVID-19; pulmonary embolism; middle-income countries.

\section{Introduction}

Coronavirus disease (COVID-19) infection is associated with increased prevalence of venous thromboembolism and pulmonary embolism (PE). ${ }^{1,2,3,4,5}$ Pulmonary embolism carries a high morbidity and mortality burden, and a high index of suspicion for underlying PE must be maintained in all COVID-19 infected patients. Hypercoagulability in COVID-19 infection occurs either because of altered haemostasis, severe inflammation, endothelial dysregulation or disseminated intravascular coagulation. ${ }^{1}$

The risk of venous thromboembolism (VTE) in patients living with HIV (PLHIV) is increased in patients who are antiretroviral therapy (ART)-naïve, those with a low cluster of differentiation (CD4) counts and virally unsuppressed. ${ }^{6}$

Dentan and colleagues showed that tuberculosis is significantly associated with VTE. They, however, found no link between TB and PE but postulated that the occurrence of PE in patients with TB (PWTB) could be explained by hypercoagulability. ${ }^{7}$ Reports of PE in PWTB in Africa are scarce. Kwas et al. have described three cases of TB associated with PE in patients from Tunisia, ${ }^{8}$ whilst Ekukwe and colleagues described another case of bilateral PE in a PWTB. ${ }^{9}$

Clinical and therapeutic challenges exist in PLHIV presenting with community-acquired pneumonia (CAP). Depending on the patient's ART compliance, viral load, certain differentials arise - especially if the patient is viral unsuppressed where in addition to COVID-19 pneumonia, one considers pneumocystis jiroveci pneumonia (PJP) and/or pulmonary TB as differentials. Empirical therapy is commenced with an antibiotic (containing a combination of trimethoprim 
and sulfamethoxazole) plus corticosteroid therapy for PJP with amoxicillin-clavulanic acid and azithromycin for CAP. ${ }^{10}$

We describe the following typical patient encountered in clinical practice to demonstrate the need for maintaining a high level of clinical vigilance for $\mathrm{PE}$ in patients with coexistent HIV, TB and COVID-19 infection. No data exists, describing the occurrence of PE in such a patient co-infected with all three infectious conditions.

\section{Case report}

Miss B.N.S., a 44-year-old female living with HIV since 1997, had defaulted ART since 2012 and was virologically unsuppressed (viral load of 23358 copies/mL, CD4 = 66 cells $/ \mu \mathrm{L}$ ). She presented on 22/09/2020 with a 1-week history of constitutional symptoms (poor appetite, night sweats and easy fatigability) associated with a non-productive cough and shortness of breath. No symptoms of fever, sore throat, anosmia or dysgeusia were elicited. Clinical examination revealed a chronically illlooking patient, tachycardia (133 beats/min), tachypnoea (22 breaths/min) and hypoxic at room air (oxygen saturation of $88 \%$ ). Chest auscultation revealed crepitations in the mid and lower zones of her right lung. Chest radiograph (Figure 1) showed bilateral central and peripheral ground-glass opacification (GGO), greater involvement of the right lung.

Blood investigations revealed results as per Table 1. Based on the patient's history, clinical, radiological and biochemical findings, a diagnosis of CAP was made, and she was started empirically on amoxicillin-clavulanic acid, azithromycin, oral trimethoprim/sulfamethoxazole, prednisone and prophylactic clexane ${ }^{\circledR} 60 \mathrm{mg}$ daily. Nasopharyngeal swab and sputa were sent for COVID-19 and TB polymerase chain reaction (PCR). A day later, the COVID-19 PCR result returned as positive. She was initiated onto dexamethasone, vitamin D, zinc, thiamine, ascorbic acid and therapeutic anticoagulation (enoxaparin $60 \mathrm{mg}$ BD). Whilst in the ward she remained hypoxic requiring $100 \%$ rebreather mask to maintain an oxygen saturation of over $90 \%$. The sputa TB PCR test returned positive on $24 / 09 / 2020$, and the patient was initiated onto anti-tuberculosis treatment (Rifafour ${ }^{\circledR} 3$ tablets with pyridoxine $25 \mathrm{mg}$ daily).

However, despite being on treatment for PJP, pulmonary $\mathrm{TB}$ and $\mathrm{CAP}$, the patient remained hypoxic with a Wells' score of 3 (heart rate $>100 \mathrm{bpm}$ and prolonged immobilisation) putting her at moderate risk of developing a PE. ${ }^{11}$ A CTPA was ordered and revealed bilateral GGO and left lower lobe subsegmental pulmonary emboli (Figure 2).

No evidence of deep vein thrombosis was found. Warfarin $5 \mathrm{mg}$ daily was added to her existing anticoagulation regimen.

The final diagnosis made in Miss B.N.S. was that of a PLHIV, virologically unsuppressed, who defaulted ART with a CD4 of 66 with confirmed:

- Severe COVID-19:12,13,14

- Pulmonary tuberculosis

- Pulmonary embolism

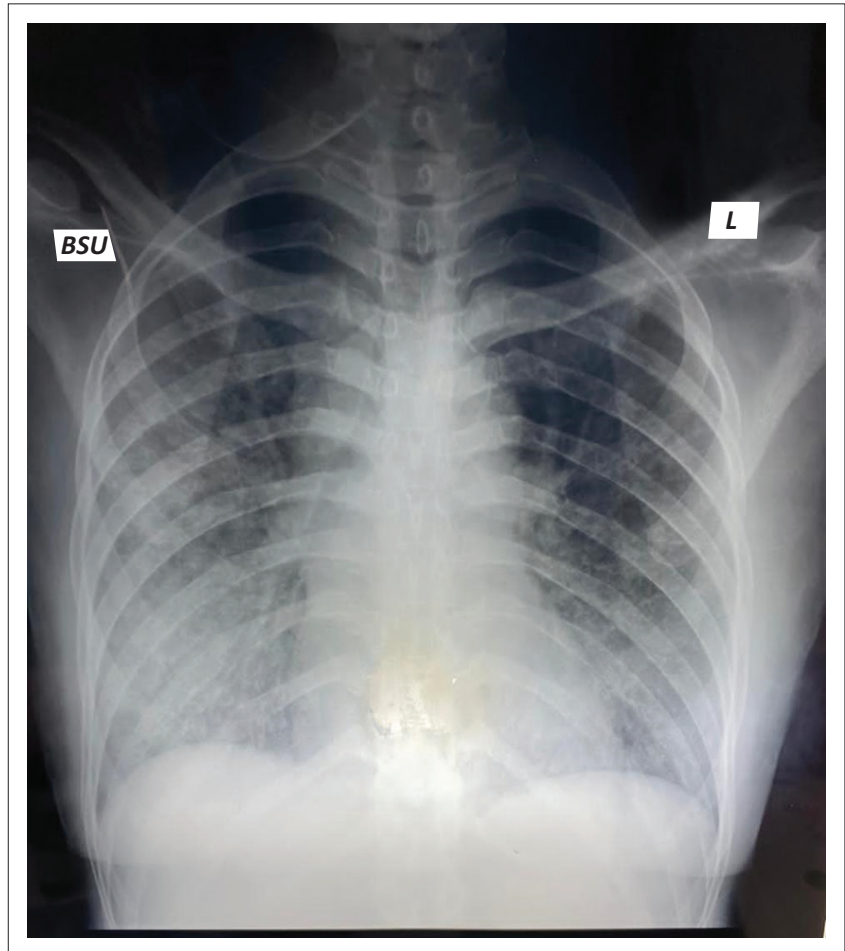

FIGURE 1: Chest radiograph (postero-anterior view).

TABLE 1: Results of laboratory investigations.

\begin{tabular}{|c|c|c|c|c|}
\hline Variables & $22 / 09 / 2020$ & $30 / 09 / 2020$ & $04 / 10 / 2020$ & $07 / 10 / 2020$ \\
\hline C-reactive protein (CRP) $\mathrm{mg} / \mathrm{L}$ [range $<10 \mathrm{mg} / \mathrm{L}$ ] & 90 & 182 & 83 & - \\
\hline White blood cell count [range $* 10^{9} /$ L] & 11.9 & 11.0 & 6.7 & - \\
\hline $\begin{array}{l}\text { Procalcitonin [range } 0.25 \mathrm{ug} / \mathrm{L}-0.5 \mathrm{ug} / \mathrm{L} \text { indicating } \\
\text { possibility of localised bacterial infection] }\end{array}$ & - & 0.35 & - & - \\
\hline $\begin{array}{l}\text { D-Dimer } \\
\text { [Range } 0.0 \mathrm{mg} / \mathrm{L}-0.25 \mathrm{mg} / \mathrm{L} \text { ] }\end{array}$ & - & 1.10 & - & - \\
\hline $\begin{array}{l}\text { International normalised ratio (INR) } \\
\text { [range 0.89-1.13] }\end{array}$ & - & 1.26 & 3.40 & 3.92 \\
\hline $\begin{array}{l}\text { Beta-D-glucan } \\
\text { [Positive }>80 \mathrm{pg} / \mathrm{mL}]\end{array}$ & - & $>500$ & - & - \\
\hline Hepatitis A, B, C serology & Negative & - & - & - \\
\hline Rapid plasma reagin (RPR) & Negative & - & - & - \\
\hline Cryptococcal antigen test & Negative & - & - & - \\
\hline
\end{tabular}




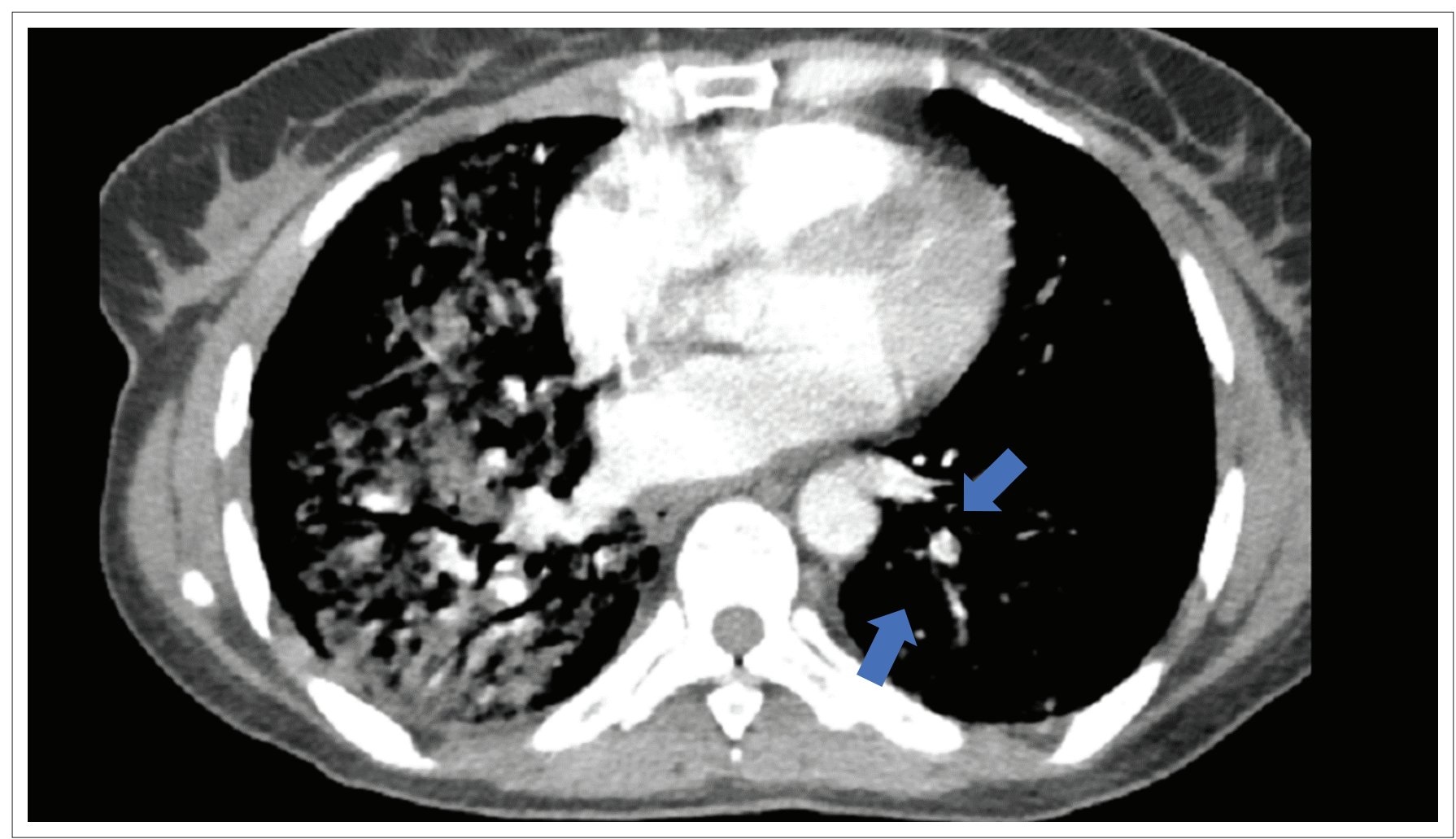

FIGURE 2: Computed tomography pulmonary angiogram showing filling defect in left lower lobe subsegmental pulmonary artery.

- Pneumocystis iirovecii pneumonia (clinical diagnosis plus a positive serum B-D-glucan).

She remained hypoxic needing prolonged oxygen supplementation until Day 17 post-admission. On Day 18, she was transferred to a step-down facility off oxygen to continue with her anticoagulation and TB treatment with a view to restarting ART in 6-8 weeks.

\section{Discussion}

Individually, HIV, TB and COVID-19 can predispose to thromboembolism. This case report describes the presence of $\mathrm{PE}$ in a patient with all aforementioned infectious diseases and the complexities associated with diagnosis in a developing country. No literature could be found on the combination of HIV, TB, COVID-19 and the development of $\mathrm{PE}$ in a single patient.

Daily clinical patient re-evaluation is a necessity even in the times of COVID-19. This is often neglected as clinical staff are afraid of their well-being and resort to making notes without careful patient re-examination. Together with clinical examination, review of blood investigations and patient's oxygen consumption needs, a management plan could be formulated.

The plasma D-dimer test has a low specificity and can be raised in a multitude of conditions including HIV-infection, TB, VTE, PE, COVID-19, pneumonia and increased age. ${ }^{15,16,17,18}$ This limited its use in differentiating between the four coexistent medical conditions in our patient, all of which are known to cause elevations in D-dimer levels. This highlights the complexity of diagnosing PE in the context of HIV, TB and COVID-19 infection.

The debate on the use of thromboprophylaxis in patients hospitalised with COVID-19 is ongoing with most studies currently advocating for its use. ${ }^{19,20,21}$ Prophylactic anticoagulation has long been recommended for at-risk inpatients with medical conditions such as HIV and/or TB. ${ }^{22,23}$ Despite being on prophylactic enoxaparin, our patient still developed a PE. This is similar to what Klok et al. and Tang et al. showed in their studies. ${ }^{9,24}$

Pulmonary embolism remains a great masquerader and clinicians must maintain a level of vigilance for diagnosing this life-threatening medical condition, more especially during the COVID-19 infection era.

\section{Acknowledgements Competing interests}

The authors have declared that no competing interest exists.

\section{Authors' contributions}

The principal author (S.P.) made substantial contributions to conception and design of the work, writing of the article and final approval and agreed to be accountable for all aspects of the research. The co-author (N.M.) made substantial contributions to conception of the work, critically reviewed and edited the draft and final approval and agreed to be accountable for all aspects of the research. 


\section{Ethical consideration}

Approval was obtained from the patient, King Edward VIII Hospital and the KwaZulu-Natal Department of Health.

\section{Funding information}

This research received no specific grant from any funding agency in the public, commercial or not-for-profit sectors.

\section{Data availability statement}

Data sharing is not applicable to this article as no new data were created or analysed in this study.

\section{Disclaimer}

The views and opinions expressed in this article are those of the authors and do not necessarily reflect the official policy or position of any affiliated agency of the authors.

\section{References}

1. Fauvel C, Weizman O, Trimaille A, et al. Pulmonary embolism in COVID-19 patients: A French multicentre cohort study. ESC. 2020;41:3058-3068. https:// doi.org/10.1093/eurheartj/ehaa500

2. Dentan C, Epaulard O, Seynaeve D, Gently C, Bosson JL. Active tuberculosis, and venous thromboembolism: Association according to international classification of diseases, ninth revision hospital discharge diagnosis codes. CID. 2014;58(4):495-501. https://doi.org/10.1093/cid/cit780

3. Kwas $\mathrm{H}$, Habibech $\mathrm{S}$, Zendah I, Elmjendel I, Ghedira $\mathrm{H}$. Pulmonary embolism and tuberculosis. Asian Cardiovascular and Thoracic Annals. 2014;22(4):487-490. https://doi.org/10.1177/0218492313485071

4. Crum-Cianflone NF, Weekes J, Bavaro M. Thromboses among HIV-infected patients during the highly active antiretroviral therapy era. AIDS Patient Care STDS. 2008;22(10):771-778. https://doi.org/10.1089/apc.2008.0010

5. Ekukwe NC, Bain LE, Jingi AM, et al. Bilateral pulmonary embolism in a patient with pulmonary tuberculosis: A rare association in Yaounde, Cameroon. Pan Afr Med J. 2014;17:262. https://doi.org/10.11604/pamj.2014.17.262.4107

6. Danzi GB, Loffi M, Galeazzi G, Gherbesi E. Acute pulmonary embolism and COVID-19 pneumonia: A random association? Eur Heart J. 2020;41:1858. https:// doi.org/10.1093/eurheartj/ehaa254

7. Zhang Y, Xiao M, Zhang S. Xia Peng, Cao W. Coagulopathy and antiphospholipid antibodies in patients with COVID-19. N Engl J Med. 2020;383:e38. https://doi. org/10.1056/NEJMc2007575
8. Xie Y, Wang X, Yang P, Zhang S. COVID-19 complicated by acute pulmonary embolism. Radiology: Cardiothoracic Imaging. 2020;2(2):e200067. https://doi. org/10.1148/ryct.2020200067

9. Klok FA, Kruip MJHA, Van der Meer NJM, et al. Incidence of thrombotic complications in critically ill ICU patients with COVID-19.Thromb Res. 2020;191:145-147. https://doi.org/10.1016/j.thromres.2020.04.013

10. Boyles TH, Brinck A, Calligaro GL, et al. South African guidelines for the management of community-acquired pneumonia in adults. JTD. 2017;9(6):1469-1502. https://doi.org/10.21037/jtd.2017.05.31

11. Wells PS, Anderson DR, Rodger M, Ginsberg JS, Kearon C. Derivation of a simple clinical model to categorize patients probability of pulmonary embolism: Increasing the models utility with the SimpliRED D-dimer. Thromb Haemost. 2000;83(3):416-420. https://doi.org/10.1055/s-0037-1613830

12. Zhou F, Yu T, Du R, et al. Clinical course and risk factors for mortality of adult inpatients with COVID-19 in Wuhan, China: A retrospective cohort study. Lancet. 2020;395(10229):1054-1062. https://doi.org/10.1016/S0140-6736(20)30566-3

13. Chen L, Liu HG, Liu W, et al. Analysis of clinical features of 29 patients with 2019 novel coronavirus pneumonia. Chin J Tubercul Respir Dis. 2020.;43(0):E005. https://doi.org/10.3760/cma.j.issn.1001-0939.2020.0005

14. Zhang JJ, Dong $\mathrm{X}$, Cao YY, et al. Clinical characteristics of 140 patients infected with SARS-CoV-2 in Wuhan, China. Allery. 2020;75(7):1730-1741. https://doi. org/10.1111/all.14238

15. Kabrhel C, Courtney DM, Camargo CA, et al. Factors associated with positive D-dimer results in patients evaluated for pulmonary embolism. Acad Emerg Med. 2010;17(6):589-597. https://doi.org/10.1111/j.1553-2712.2010.00765.x

16. Guan WJ, Ni ZY, Hu Y. China medical treatment expert group for COVID-19. Clinical characteristics of coronavirus disease 2019 in China. N Engl J Med. 2020;382(18):1708-1720. https://doi.org/10.1056/NEJMoa2002032

17. Borges AH, O'Connor JL, Phillips AN, et al. Factors associated with D-Dimer levels in HIV-infected individuals. PLoS One. 2014;9(3):e90978. https://doi.org/10.1371/ journal.pone.0090978

18. Kutiyal AS, Gupta N, Garg S, Hira HS. A study of haematological and haemostasis parameters and hypercoagulable state in tuberculosis patients in Northern India and the outcome with anti-tubercular therapy. J Clin Diagn Res. 2017;11(2):09-13. https://doi.org/10.7860/JCDR/2017/24022.9249

19. Nankarni GN, Lala A, Bagiella E, et al. Anticoagulation, bleeding, mortality and pathology in hospitalized patients with COVID-19. I Am Coll Cardiol. 2020;76(16):1815-1826. https://doi.org/10.1016/j.jacc.2020.08.041

20. Tang $\mathrm{N}$, Bai $\mathrm{H}$, Chen $\mathrm{X}$, et al. Anticoagulant treatment is associated with decreased mortality in severe coronavirus disease 2019 patients with coagulopathy. J Throm Haemost. 2020;18(5):1094-1099. https://doi.org/10.1111/jth.14817

21. Lin L, Lu L, Cao W, Li T. Hypothesis for potential pathogenesis of SARS-CoV2 infection-a review of immune changes in patients with viral pneumonia. Emerg Microbes Infect. 2020;9(1):727-732. https://doi.org/10.1080/22221751.2020.17 46199

22. Maynard GA, Morris TA, Jenkins IH, et al. Optimizing prevention of hospitalacquired venous thromboembolism (VTE): Prospective validation of a VTE risk assessment model. J Hosp Med. 2010. https://doi.org/10.1002/jhm.562

23. Piazza G, Fanikos J, Zayaruzny M, Goldhaber SZ. Blood coagulation, fibrinolysis and cellular haemostasis: Venous thromboembolic events in hospitalized medical patients. Thromb Haemost. 2009;102(3):505-510. https://doi.org/10.1160/ TH09-03-0150

24. Tang N, Li D, Wang X, Sun Z. Abnormal coagulation parameters are associated with poor prognosis in patients with novel coronavirus pneumonia. J Thromb Haemost. 2020;18(4):844-847. https://doi.org/10.1111/jth.14768 